\title{
ANALYSIS AND MODELING OF ENERGY DEMAND STRUCTURE IN IRAN'S BUILDINGS AND RELATED INDUSTRIES
}

\author{
Seyed Morteza Emami ${ }^{1}$, Mehdi Ravanshadnia ${ }^{2 *}$, Mahmood Rahimi $^{3}$ \\ ${ }^{I}$ Department of Civil Engineering, Science and Research Branch, Islamic Azad University, Tehran, Iran; \\ ${ }^{2 *}$ Department of Civil Engineering, Science and Research Branch, Islamic Azad University, Tehran, Iran; \\ ${ }^{3}$ Department of Urban Planning, Central Tehran Branch, Islamic Azad University, Tehran, Iran; \\ ${ }^{2 *}$ Corresponding Author Mehdi Ravanshadnia e-mail: ravanshadnia@gmail.com;
}

Received July, 2018; Accepted December, 2018; Published January, 2019;

DOI: https://doi.org/10.31407/ijees9116

UOI license: http://u-o-i.org/1.01/ijees/75334318

\begin{abstract}
In this paper, the demand of the energy carriers in Iran is analyzed and modeled for the country's largest consumer, buildings and related industries, in the status quo and future perspective. To this end, the building sector is divided into two sections: household section (residential buildings) and services (business-office and service buildings) according to the ISIC classification, each of which is subdivided into other sub-sections. In addition, building-related industries include some non-metallic minerals and basic metals industries. Given that scenario-based energy planning helps to increase the understanding of different probabilities in the future, the future perspective of the system is modeled according to the 2035 horizon using the LEAP modeler in the "reference" scenario, which indicates continuation of the status quo of the energy system in the future. The results of the modeling indicate an increasing demand for energy as so it is expected that the demand for energy carriers in buildings and related industries to reach up to 1040.6 million barrels of oil equivalents in 2035, from 559.8 million barrels in 2014. Therefore, in order to reduce energy consumption, solutions are modeled and analyzed according to the scenarios for "Improvement of energy consumption in buildings and related industries", and then the greenhouse gas emissions and their environmental impacts are examined.
\end{abstract}

Key words: Buildings and Related Industries, Energy Demand, Energy Policy-making, Oil, Gas and Electricity, Modeling, LEAP, Scenario 